\title{
Esterco bovino líquido em luvissolo sódico: I. Resposta biométrica e produtiva do maracujazeiro amarelo*
}

\author{
Liquid bovine manure in luvissol sodic: I. Biometric and productive \\ response of yellow passion fruit plants
}

\begin{abstract}
Vinícius Batista Campos ${ }^{1}$, Lourival Ferreira Cavalcante ${ }^{2,6}$, Stella Silva Prazeres Campos ${ }^{3}$, Hans Raj Gheyi ${ }^{4,} 6$, Lúcia Helena Garófalo Chaves ${ }^{5,6}$, Francisco de Oliveira Mesquita ${ }^{2}$
\end{abstract}

\section{RESUMO}

Objetivou-se com o presente estudo, avaliar o efeito do biofertilizante bovino líquido na biometria e produção de matéria seca das mudas de maracujazeiro amarelo cultivado em Luvissolo sódico. O experimento foi desenvolvido no departamento de Solos e Engenharia Rural do CCA, UFPB, no período entre agosto e outubro de 2008, distribuído em blocos casualizados em parcelas subdivididas, estando nas parcelas níveis de biofertilizante bovino líquido de 0, 25, 50, 75 e 100\% em volume correspondente a $10 \%(250 \mathrm{~mL})$ do volume do substrato e nas subparcelas cinco períodos de avaliações das plantas $(45,60,75,90$ e 105 dias após a semeadura) em quadruplicata. A aplicação do biofertilizante foi feita 30 dias antes da semeadura, a seguir aplicou-se uma lavagem do solo (dois dias após do fornecimento) e, uma segunda aplicação do biofertilizante, 48 horas antes da semeadura, seguida de uma lavagem semelhantemente à da primeira aplicação. Utilizou-se na irrigação água não salina, adicionando-se a cada 24 horas, o volume evapotranspirado nesse período, baseado no processo de pesagem do vaso. O aumento do nível do insumo orgânico proporcionou maior altura das plantas, diâmetro caulinar, número de folhas, área foliar e matéria seca total, superando a testemunha em 134,78; 114,72; 127,35, 416,54 e 107,97\%, respectivamente.

Palavras-chave: Passiflora edulis Sims., biofertilizante bovino, matéria seca, sodicidade.

\begin{abstract}
The objective of the present study was to evaluate the effect of liquid bovine biofertilizer on the biometry and the dry matter production of yellow passion fruit seedlings grown on sodic Luvissol. The experiment was performed in the Department of Soil and Rural Agricultural Engineering of the Center of Agricultural Sciences (CCA), Federal University of Paraíba (UFPB), from August to October 2008. The experimental design was that of randomized blocks in split plots, where the plots were the levels of liquid biofertilizer at 0, 25, 50, 75 and $100 \%$ by volume of $10 \%$ of the total substratum volume $(250 \mathrm{~mL})$, the subplots were the five plant evaluation periods (45, 60, 75, 90 and 105 days after the sowing); the experiment was performed in quadruplicate. The application of biofertilizer was made 30 days before sowing, followed by a washing of the soil (two days after of biofertilizer application); a second application of the biofertilizer was made 48 hours before sowing, followed by a soil washing similar to that of the first application. Non-saline water was used for irrigation, adding the water equivalent to the evapotranspiration rate per 24 hours, based on weighing the pots. The increased level of organic matter input provided greater plant height and stem diameter, as well as greater leaf number, foliar area and total dry matter, surpassing the control by 134.78; 114.72; 127.35; 416.54 and 107.97\%, respectively.

Key words: Passiflora edulis Sims., bovine biofertilizer, dry matter, sodicity.
\end{abstract}

\section{Introdução}

As plantas sob condições naturais encontramse submetidas às constantes mudanças ambientais, tendo como consequência uma série de estímulos que influenciam no desenvolvimento e rendimento dos cultivos. Dos fatores que geram estresse incluem-se aqueles provenientes da ação de organismos vivos

* Parte da dissertação apresentada ao Programa de Pós-Graduação em Manejo de Solo e Água do CCA/UFPB.

1 Instituto Federal de Educação, Ciência e Tecnologia do Amapá, Campus Laranjal do Jarí, AP. 68920-000, doutorando em Engenharia Agrícola, CTRN, UFCG, Campina Grande-PB. Email: viniciuspgmsa@ hotmail.com

2 Universidade Federal da Paraíba, Departamento de Solos e Engenharia Rural, Areia, PB.

3 Universidade Federal do Ceará, Programa de Pós-Graduação em Solos e Nutrição de Plantas, Fortaleza, CE.

4 Universidade Federal do Recôncavo da Bahia, Núcleo de Engenharia de Água e Solo, Cruz das Almas, BA.

5 Universidade Federal de Campina Grande, Unidade de Engenharia Agrícola, Campina Grande, PB.

6 Pesquisador INCTSal. 
e atividades antropogênicas, mudanças climáticas, escassez ou excesso de água, intensidade luminosa, carência de nutrientes e salinidade excessiva (Chynnusamy et al., 2005).

Os solos situados em regiões áridas e semiáridas quando submetidos à prática da irrigação apresentam grandes possibilidades de se tornarem salinos. Estimativas da FAO (2004) informam que dos 250 milhões de hectares irrigados no mundo, aproximadamente $50 \%$ já apresentam problemas de salinização e que 10 milhões de hectares são abandonados anualmente em virtude dessa problemática.

Nas áreas intensamente cultivadas sob irrigação, como nos perímetros irrigados e nos pólos produtivos do Nordeste brasileiro (Lopes et al., 2008), além de outros lugares do mundo, a exemplo do Vale do Jordão (Al-Zu'Bi, 2007) e Irã (Mostafazadeh-Fard et al., 2009), a maior parte dos sais são transportados ao solo através da água de irrigação, tanto pelo conteúdo salino da água quanto pelo manejo deficitário da irrigação e drenagem deficiente dos solos para lixiviação dos sais.

Quando se trata genericamente de solo salinosódico ou sódico, para a recuperação dessas áreas torna-se indispensável à utilização de corretivos para neutralizar o efeito do cátion dispersante $\left(\mathrm{Na}^{+}\right)$do solo. Produtos como gesso agrícola, ácido sulfúrico, vinhaça, são corretivos químicos com alta eficiência técnica. Entretanto, novas formas de reabilitação de solos comprometidos por sais vêm sendo estudadas a exemplo da matéria orgânica (Gheyi et al., 1995; Cavalcante et al., 2002) e ainda vermicompostos (Ansari, 2008).

O uso de biofertilizante bovino na agricultura não é recente, mas, com o crescimento da agricultura orgânica, o emprego de formas alternativas no sistema de produção das culturas vem sendo incrementado. Atualmente, o insumo orgânico é mais frequentemente utilizado para controle de insetos, bactérias, fungos e actinomicetos (Kupper et al., 2006), mas também tem sido utilizado diretamente no solo não salino para cultivo do maracujazeiro amarelo (Cavalcante et al., 2008). Alguns estudos também se encontram na literatura versando sobre a interação do biofertilizante bovino x salinidade da água de irrigação (Sousa, 2006; Campos et al., 2009; Cavalcante et al., 2010), porém as informações da aplicação de esterco líquido fermentado em solos afetados por sais solúveis e sódio trocável são ainda incipientes.
Nesse sentido, objetivou-se avaliar as respostas biométricas do maracujazeiro amarelo até 105 dias após a semeadura, submetido ao emprego de biofertilizante bovino líquido.

\section{Material e Métodos}

\section{Área de estudo}

A pesquisa foi conduzida no período de agosto a dezembro de 2008, em casa de vegetação do Departamento de Solos e Engenharia Rural (DSER) do Centro de Ciências Agrárias (CCA), Campus II, Universidade Federal da Paraíba (UFPB), localizado no município de Areia, $\mathrm{PB}$, na microrregião do Brejo paraibano, cujas coordenadas geográficas são: 6 58' 12" S e 35'42'15" W, a uma altitude de $619 \mathrm{~m}$.

Segundo a classificação de Köppen, o clima da região é do subtipo tropical sub-úmido (quente úmido, com chuvas de março a agosto), temperatura média anual oscilando entre 22 e $26^{\circ} \mathrm{C}$ e umidade relativa do ar entre 75 e $87 \%$. Os dados referentes à temperatura média e umidade relativa do ar da área experimental no período de condução da pesquisa encontram-se na Figura 1.

Como substrato foi utilizado material de um LUVISSOLO CRÔMICO caráter sódico proveniente do Instituto Federal de Educação, Ciência e Tecnologia da Paraíba, Campus Sousa, coletados na profundidade $0-20 \mathrm{~cm}$ do perfil. Após a coleta, o material de solo foi destorroado e posto para secar ao ar na sombra; em seguida foi passado em peneira de malha de $6 \mathrm{~mm}$. Desse material foram retiradas amostras passadas na peneira de $2 \mathrm{~mm}$ de malha, obtendo-se a terra fina seca ao ar (TFSA), para a caracterização física e química, nos Laboratórios de Física, Química e fertilidade do solo do DSER/ CCA/UFPB.

Fisicamente o solo apresentava 652, 306, 42 e $25 \mathrm{~g} \mathrm{~kg}^{-1}$ de areia, silte, argila e argila dispersa em água, respectivamente; densidade do solo e densidade de partículas de 1,71 e $2,66 \mathrm{~kg} \mathrm{dm}^{-3}$, resultando numa porosidade total de $0,35 \mathrm{~m}^{3} \mathrm{~m}^{-3}$ e valor de água disponível de $17,8 \mathrm{~g} \mathrm{~kg}^{-1}$.

Quanto aos atributos de fertilidade, foi caracterizado como alcalino ( $\mathrm{pH}=9,46)$, com os seguintes teores: $\mathrm{P}\left(\mathrm{mg} \mathrm{dm}^{-3}\right)=71,06 ; \mathrm{K}^{+}\left(\mathrm{cmol}_{\mathrm{c}} \mathrm{dm}^{-3}\right)=0,21$; $\mathrm{Ca}^{2+}\left(\mathrm{cmol}_{\mathrm{c}} \mathrm{dm}^{-3}\right)=3,03 ; \mathrm{Mg}^{2+}\left(\mathrm{cmol}_{\mathrm{c}} \mathrm{dm}^{-3}\right)=1,45$; $\mathrm{Na}^{+}\left(\mathrm{cmol}_{\mathrm{c}} \mathrm{dm}^{-3}\right)=2,56$; soma de bases $\left(\mathrm{cmol}_{\mathrm{c}}\right.$ $\left.\mathrm{dm}^{-3}\right)=7,25$; capacidade de troca catiônica $\left(\mathrm{cmol}_{\mathrm{c}}\right.$ $\left.\mathrm{dm}^{-3}\right)=7,25$, resultando no caráter eutrófico. 
A

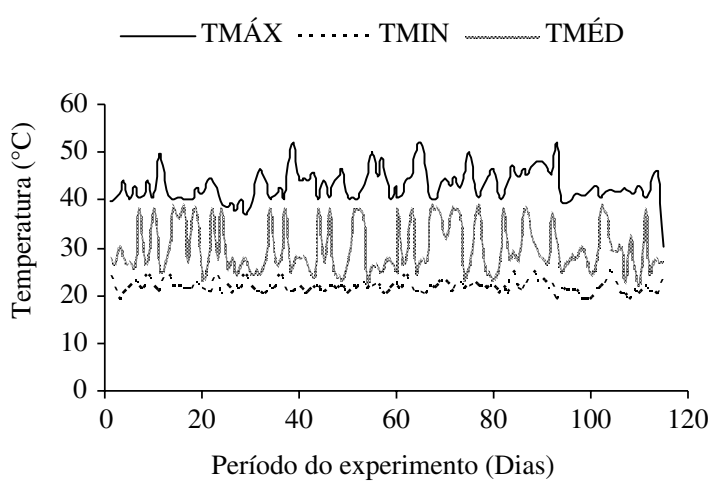

B
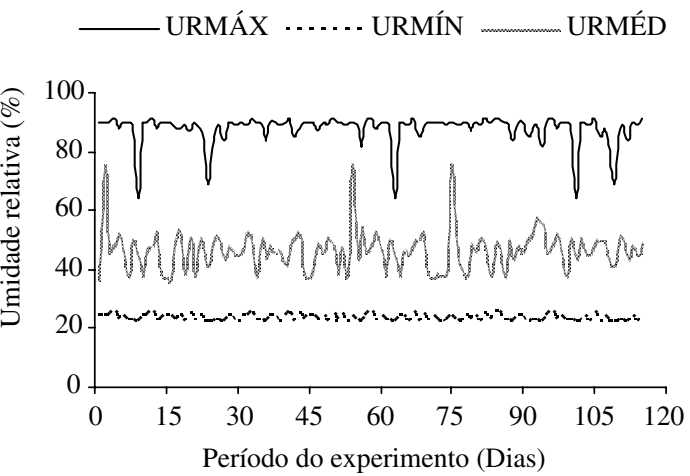

Figura 1. Valores de temperatura (A) e umidade relativa do ar (B) no interior do abrigo protegido no período de condução do experimento.

No que diz respeito à salinidade, o material utilizado apresentou os seguintes valores: $\mathrm{pH}=8,38$; $\mathrm{Ca}^{2+}\left(\mathrm{mmol}_{\mathrm{c}} \mathrm{L}^{-1}\right)=2,50 ; \mathrm{Mg}^{2+}\left(\mathrm{mmol}_{\mathrm{c}} \mathrm{L}^{-1}\right)=3,87$ $\mathrm{Na}^{+}\left(\mathrm{mmol}_{\mathrm{c}} \mathrm{L}^{-1}\right)=25,74 ; \mathrm{K}^{+}\left(\mathrm{mmol}_{\mathrm{c}} \mathrm{L}^{-1}\right)=0,35$; $\mathrm{Cl}^{-}\left(\mathrm{mmol}_{\mathrm{c}} \mathrm{L}^{-1}\right)=18,75 ; \mathrm{CO}_{3}{ }^{2-}\left(\mathrm{mmol}_{\mathrm{c}} \mathrm{L}^{-1}\right)=0,00$; $\mathrm{HCO}_{3}^{-}\left(\mathrm{mmol}_{\mathrm{c}} \mathrm{L}^{-1}\right)=5,50 ; \mathrm{SO}_{4}^{2-}\left(\mathrm{mmol}_{\mathrm{c}} \mathrm{L}^{-1}\right)=0,00$; condutividade elétrica $\left(\mathrm{dS} \mathrm{m}^{-1}\right)=2,30$; relação de adsorção de sódio $\left(\mathrm{mmol} \mathrm{L}^{-1}\right)^{0,5}=14,42$ e percentagem de sódio trocável $(\%)=35,31$, conferindo o caráter sódico, segundo Richards (1954).

\section{Tratamentos e delineamento experimental}

Os tratamentos foram dispostos em blocos casualizados em parcelas subdivididas no tempo, sendo as parcelas compostas por cinco doses de biofertilizante bovino e nas subparcelas as idades das plantas para avaliação. O biofertilizante foi aplicado ao solo na forma líquida aos níveis de 0 ; $25 ; 50 ; 75$ e $100 \%$ em volume correspondente a $10 \%$ (250 mL) do volume do substrato diluído em água, exceto para o maior nível (Tabela 1) e, cinco idades de avaliação das plantas aos 45, 60, 75, 90, 105 dias após a semeadura (DAS), com quatro repetições, perfazendo um total de 100 unidades experimentais.

\section{Condução do experimento}

Cada unidade experimental foi constituída por um vaso plástico preto de forma cônica com diâmetro superior e inferior de 18,5 e $10,5 \mathrm{~cm}$, respectivamente, e altura de $17,5 \mathrm{~cm}$ com capacidade para três litros contendo $2,5 \mathrm{~kg}$ de solo seco ao ar e passado em peneira de $6 \mathrm{~mm}$ com $2 \mathrm{~cm}$ de
Tabela 1. Composição química da água e das misturas do biofertilizante bovino e águas utilizadas no experimento.

\begin{tabular}{lcrrrr}
\hline & \multicolumn{5}{c}{ Biofertilizante $(\%)$} \\
\hline \multicolumn{1}{c}{ Atributos } & \multicolumn{1}{c}{$0^{*}$} & \multicolumn{1}{c}{25} & 50 & 75 & 100 \\
\hline $\mathrm{pH}$ & 6,11 & 6,31 & 6,43 & 6,55 & 6,78 \\
$\mathrm{Ca}^{2+}\left(\mathrm{mmol}_{\mathrm{c}} \mathrm{L}^{-1}\right)$ & 1,25 & 3,91 & 6,21 & 9,27 & 10,53 \\
$\mathrm{Mg}^{2+}\left(\mathrm{mmol}_{\mathrm{c}} \mathrm{L}^{-1}\right)$ & 0,58 & 4,96 & 9,37 & 13,93 & 17,42 \\
$\mathrm{Na}^{+}\left(\mathrm{mmol}_{\mathrm{c}} \mathrm{L}^{-1}\right)$ & 0,92 & 2,33 & 4,01 & 4,68 & 6,24 \\
$\mathrm{~K}^{+}\left(\mathrm{mmol}_{\mathrm{c}} \mathrm{L}^{-1}\right)$ & 0,16 & 5,92 & 10,21 & 17,66 & 23,39 \\
$\mathrm{CO}_{3}{ }^{2-}\left(\mathrm{mmol}_{\mathrm{c}} \mathrm{L}^{-1}\right)$ & 0,00 & 0,00 & 0,00 & 0,00 & 0,00 \\
$\mathrm{HCO}_{3}{ }^{-}\left(\mathrm{mmol}_{\mathrm{c}} \mathrm{L}^{-1}\right)$ & 0,52 & 2,61 & 4,39 & 6,92 & 8,43 \\
$\mathrm{Cl}^{-}\left(\mathrm{mmol}_{\mathrm{c}} \mathrm{L}^{-1}\right)$ & 2,13 & 12,31 & 21,64 & 34,41 & 41,50 \\
$\mathrm{SO}_{4}{ }^{2-}\left(\mathrm{mmol}_{\mathrm{c}} \mathrm{L}^{-1}\right)$ & 0,27 & 2,12 & 3,34 & 5,29 & 7,32 \\
$\mathrm{CE}\left(\mathrm{dS} \mathrm{m}^{-1}\right)$ & 0,29 & 1,72 & 2,95 & 4,61 & 5,78 \\
$\mathrm{RAS}\left(\mathrm{mmol} \mathrm{L}^{-1}\right)^{0,5}$ & 0,96 & 1,11 & 1,43 & 1,38 & 1,67 \\
$\mathrm{Classificação}^{* *}$ & $\mathrm{C}_{1} \mathrm{~S}_{1}$ & $\mathrm{C}_{3} \mathrm{~S}_{1}$ & $\mathrm{C}_{3} \mathrm{~S}_{1}$ & $\mathrm{C}_{4} \mathrm{~S}_{1}$ & $\mathrm{C}_{4} \mathrm{~S}_{1}$ \\
\hline
\end{tabular}

$\mathrm{CE}=$ Condutividade elétrica; RAS = Relação de adsorção de sódio; * = Água de irrigação; ** = Classificação segundo Richards (1954).

brita e $2 \mathrm{~cm}$ de areia, na base do vaso, mangueira e recipiente coletor de 2 L para avaliação da condutividade elétrica do lixiviado.

O biofertilizante bovino puro foi produzido sob fermentação anaeróbica, adicionando-se partes iguais de água e esterco fresco de bovino, permanecendo em recipiente hermeticamente fechado durante 30 dias (Santos, 1992; Campos et al., 2008). A liberação do gás metano foi feita conectando-se uma das extremidades de uma mangueira na parte superior do biodigestor mantendo-se a outra imersa em um recipiente com água.

A primeira aplicação do biofertilizante ocorreu 30 dias antes da semeadura, seguida de uma lavagem, fornecendo um volume de água não salina 
equivalente a duas vezes a porosidade total do solo (1,31 L). A segunda aplicação foi realizada 48 horas antes da semeadura e, em seguida, procedendo-se a mais uma lavagem.

As sementes de maracujazeiro-amarelo (Passiflora edulis Sims.), obtidas em plantio comercial no município de Remígio-PB, foram coletadas de frutos sadios, via seleção massal e postas para secar a sombra, e, posteriormente, eliminaram-se as defeituosas. Para assegurar mudas vigorosas, testou-se a viabilidade das sementes (92\%), assegurando assim um material de boa qualidade. Foram semeadas seis sementes por unidade experimental, numa profundidade de $2 \mathrm{~cm}$ com solo previamente umedecido. A semeadura foi realizada no dia 12 de setembro de 2008. Após o período de estabilização da emergência das plântulas, aos 28 dias, realizouse o desbaste, mantendo a planta mais vigorosa por unidade experimental.

A partir da semeadura até o final do experimento as irrigações foram realizadas mediante processo de pesagem, de modo a fornecer o volume evaporado no intervalo de 24 horas, elevando a umidade do solo à capacidade de campo.

\section{Variáveis observadas e análises estatísticas}

Foi avaliada a altura das plantas com auxílio de uma régua milimetrada e o diâmetro caulinar mediante uso de paquímetro digital. O número de folhas através de contagem e a área foliar mensurada através de imagens fotográficas obtidas com câmera digital Sony 5.0 e processadas pelo software Sigma Scan Pro 5.0 Demo.

Os dados foram submetidos à análise de variância pelo teste "F" e as médias comparadas

A

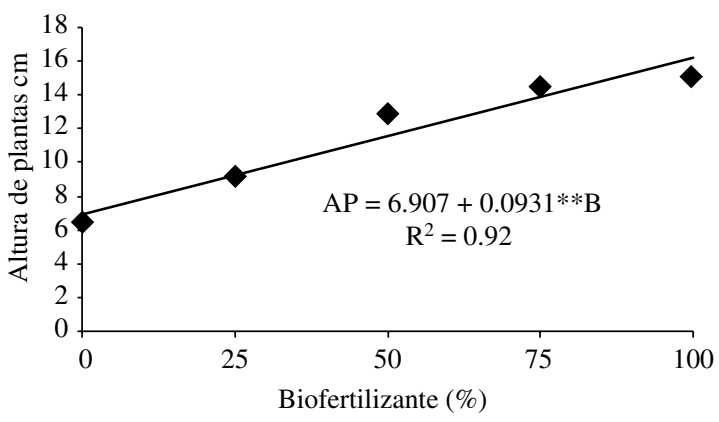

pelo teste Tukey e quantitativamente por análise de regressão (Ferreira, 2000), utilizando o software SAEG 8.0.

\section{Resultados e Discussão}

A adição do biofertilizante ao solo estimulou o crescimento em altura em função das concentrações e da idade das plantas (Figura 2). Percebe-se na Figura 2A que o insumo promoveu aumento da altura das plantas ao nível de $0,093 \mathrm{~cm}$ por incremento unitário de biofertilizante fornecido ao solo atingindo o valor máximo de $16,2 \mathrm{~cm}$ na maior dose do insumo orgânico. Conforme indicado na Figura 2B, o crescimento em altura das plantas foi linear em função da idade, com incremento diário de 0,122 $\mathrm{cm}$, atingindo basicamente o mesmo aos 105 dias nas plantas no tratamento com maior dose de biofertilizante aplicado. Mesmo ocorrendo crescimento linear em função das doses do insumo e da idade das plantas, os resultados, apesar de promissores, são inferiores à altura das plantas de até $20 \mathrm{~cm}$ aos 60 dias após a emergência, desenvolvidas em solos não salinos irrigados com água de boa qualidade, como apresenta Sousa (2006).

Tendência semelhante foi verificada também por Cavalcante et al. (2010) ao concluírem que o maracujazeiro amarelo teve o crescimento estimulado na maior concentração do biofertilizante. Essa superioridade nos tratamentos com o insumo deve-se a sua composição, por estimular a produção de substâncias vitais como solutos orgânicos, ácidos nucléicos, proteínas (Vessey, 2003), além do fornecimento de substâncias húmicas que contribuem para o crescimento vegetal (Lagreid et al., 1999).

\section{B}

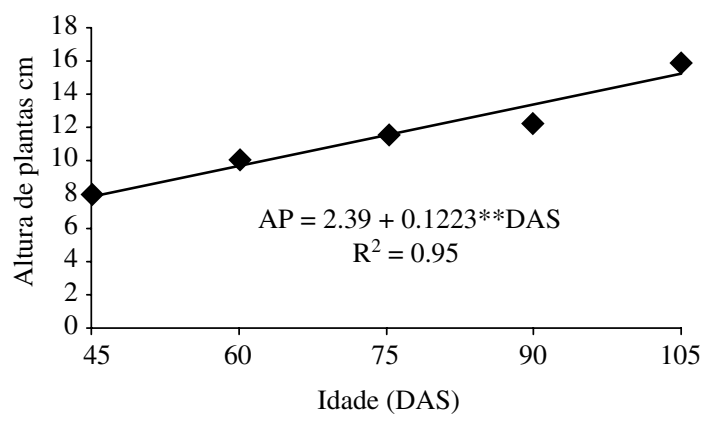

Figura 2. Altura das plantas de maracujazeiro-amarelo em função do biofertilizante bovino aplicado ao solo (A) e idade das plantas após a emergência (B). 
Estatistamente, o diâmetro caulinar do maracujazeiro amarelo foi influenciado positiviamente pela interação biofertilizante bovino e idade de avaliação das plantas (Figura 3). A variável em questão apresentou melhor desenvolvimento nos tratamentos com maiores proporções de biofertilizante bovino e nos períodos de avaliação mais prolongados, verificando-se uma variação de $41,28 \%$ nos tratamentos com $100 \%$ do insumo na última idade de avaliação (105 dias após a semeadura) em relação ao tratamento controle juntamente com a primeiro período de estudo das plantas (45 dias após a semeadura).

Essa evidência é satisfatória porque diferentes culturas submetidas a estresse salino, em geral, sofrem inibição das suas características fenológicas

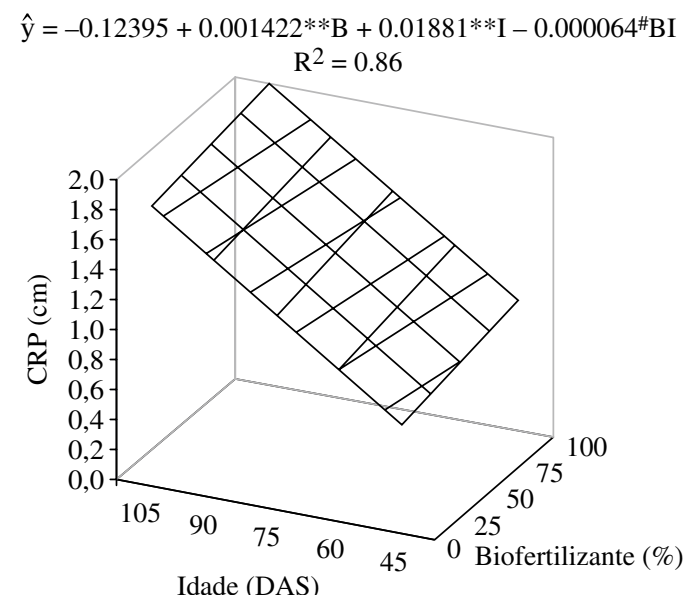

Figura 3. Diâmetro caulinar (DC) do maracujazeiro-amarelo em função do biofertilizante bovino e idade das plantas após a semeadura. "Significativo a $10 \%$ de probabilidade pelo teste $\mathrm{F}$.

A

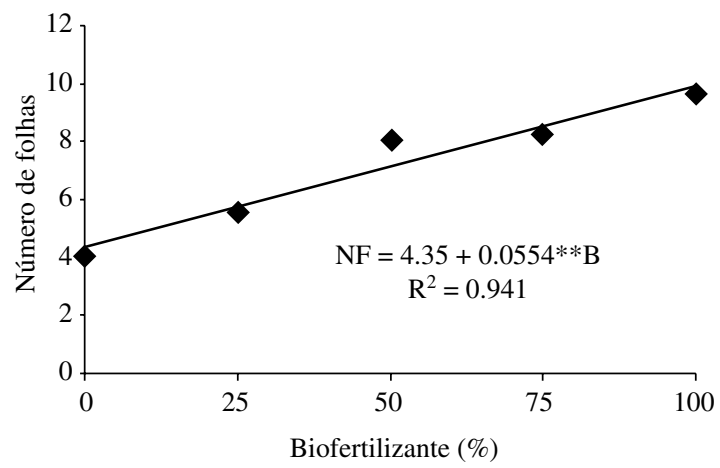

e produtivas com o tempo de exposição aos efeitos adversos dos sais. Nesse sentido, Oliveira et al. (2006), após estudarem o efeito da salinidade da água em substrato com diversas proporções de matéria orgânica, concluíram que o diâmetro do caule foi afetado positivamente pela maior quantidade matéria orgânica, tendência semelhante também apresentada por Campos et al. (2004), em substrato com biofertilizante bovino e cultivado com mamoneira. Sob condições não salinas Campos et al. (2008) registraram maior diâmetro caulinar do maracujazeiro amarelo em plantas tratadas com biofertilizante bovino puro aplicado ao solo.

De forma similar à altura de plantas, o número de folhas cresceu linearmente com o aumento da proporção de biofertilizante ao longo do período após a emergência das plântulas (Figura 4). O aumento foi de 0,057 folhas por aumento unitário do insumo utilizado com maior valor de 10,05 folhas referente às plantas do tratamento com $100 \%$ do biofertilizante (Figura 4A). Em relação à idade das plantas, o número de folhas também aumentou linearmente ao nível diário de 0,043 folhas e por conseguinte atingindo maiores valores aos 105 dias após a emergência (Figura 4B).

Pela presença de substâncias húmicas no biofertilizante e vitais às plantas, à medida que se aumentou a concentração do insumo orgânico, pode ter havido aumento do potencial osmótico na zona radicular, que se refletiu no crescimento, expansão e divisão celular, favorecendo o surgimento de maior número de folhas (Marschner, 1995).

Ao considerar que o solo é de natureza sódica, a adição de matéria orgânica na forma de esterco líquido deve ter contribuído para o deslocamento

B

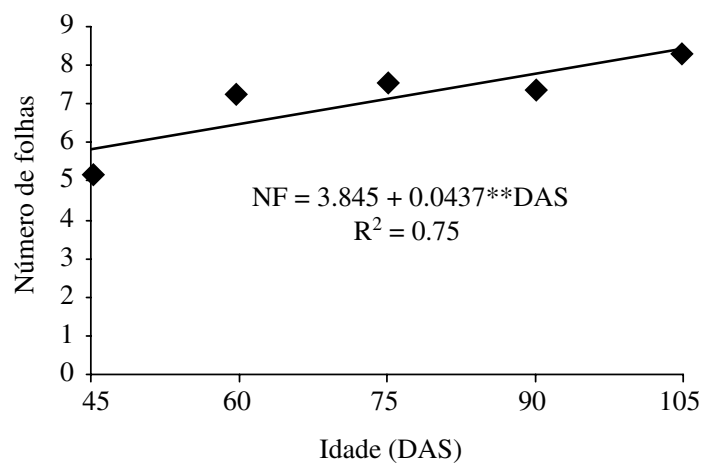

Figura 4. Número de folhas de maracujazeiro-amarelo em função do biofertilizante bovino aplicado ao solo (A) e idade das plantas após a emergência (B). 
de sódio do complexo de troca para a solução sendo parcialmente lixiviado na lavagem efetuada um dia após a aplicação do biofertilizante no solo. A tendência dos resultados foi semelhante à observada por Gheyi et al. (1995) e Cavalcante et al. (2002) após constatarem que o esterco bovino reduziu o nível de salinidade e de sodicidade de solos degradados por sódio. O menor número de folhas nos tratamentos sem aplicação de biofertilizante é devido os sais reduzirem a produção, acumulação e distribuição de fotoassimilados vitais no crescimento e desenvolvimento das plantas (Lacerda et al., 2003; Taiz \& Zeiger, 2006).

Em trabalho com o maracujazeiro amarelo irrigado com água salina em solo não salino sem e com biofertilizante bovino, Sousa (2006) constatou maior número de folhas das plantas nos tratamentos com biofertilizante comum ao nível de $10 \%$ do volume do substrato irrigado com água salina, resultando em maior número de folhas máximo de 12,01 aos 60 dias após a emergência. Comparativamente com esse valor observa-se que houve uma redução de pelo menos três folhas, e evidencia que a ação do biofertilizante expressa ser menos eficaz em reduzir os efeitos degenerativos da salinidade do solo quando comparado a água de irrigação.

Da mesma maneira da altura de plantas e número de folhas, a área foliar ajustou-se ao modelo de regressão linear crescente tanto em função da aplicação de biofertilizante quanto com a idade das plantas avaliadas (Figura 5). A elevação de $0,682 \mathrm{~cm}^{2}$ por aumento unitário do biofertilizante aplicado resultou num valor máximo de $83,61 \mathrm{~cm}^{2}$ concernente às plantas dos tratamentos com $100 \%$ de biofertilizante bovino (Figura 5A). Para a idade de avaliação, a área foliar também aumentou de forma linear diariamente $1,22 \mathrm{~cm}^{2} \mathrm{e}$, por conseguinte atingindo maiores valores aos 105 dias após a emergência (Figura 5B).

Esses resultados são superiores aos obtidos por Sousa (2006), utilizando água com condutividade elétrica de até $4 \mathrm{dS} \mathrm{m}^{-1}$ na irrigação do maracujazeiro amarelo em substrato contendo biofertilizante, entretanto são inferiores aos registrados por Soares et al. (2002) e Cruz et al. (2006), para o maracujazeiro amarelo irrigado apenas com água com problemas de sais.

O crescimento da raiz principal, assim como o diâmetro do caule respondeu aos efeitos da interação biofertilizante bovino $\mathrm{x}$ idade de avaliação das plantas (Figura 6). O maior comprimento da raiz principal correspondeu à maior dose de biofertilizante (100\%) e aos 105 dias de avaliação após a semeadura, oco-

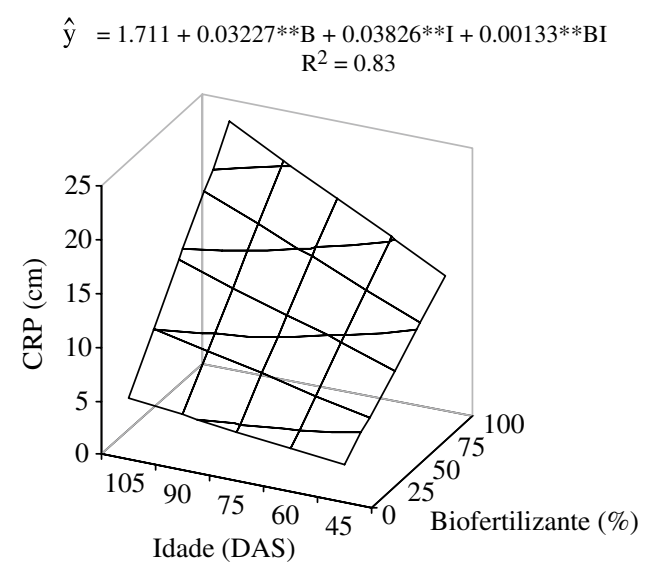

Figura 6. Comprimento da raiz principal (CRP) do maracujazeiro amarelo em função do biofertilizante bovino e idade das plantas de avaliação das plantas após a semeadura.
A

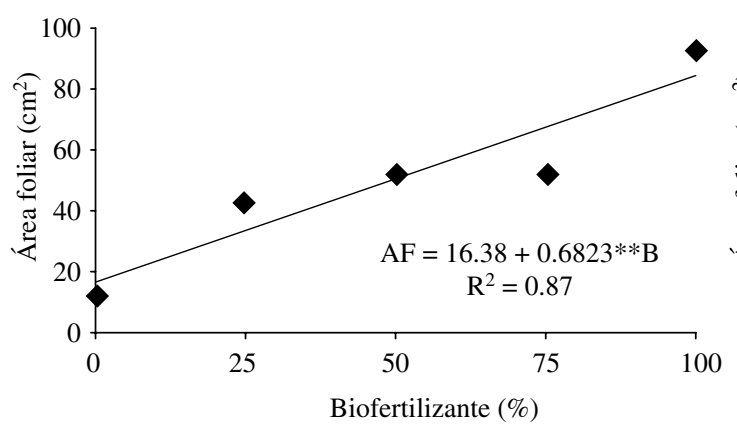

B

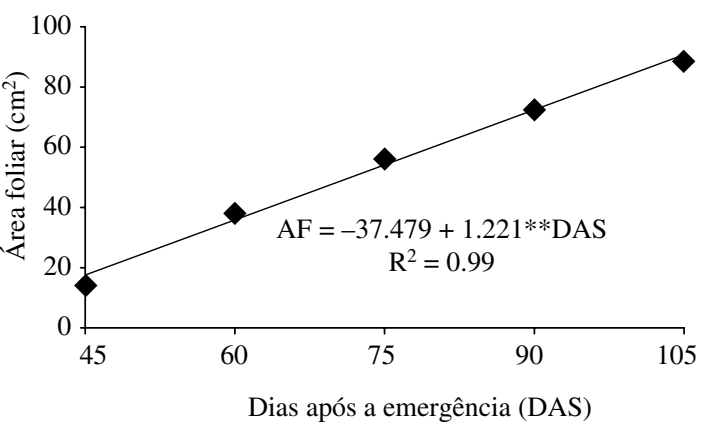

Figura 5. Área foliar do maracujazeiro amarelo em função do biofertilizante bovino aplicado ao solo (A) e idade das plantas após a emergência (B). 
rrendo um incremento de $99,85 \%$ em comparação à ausência de biofertilizante no solo.

As raízes, diferentemente da parte aérea, têm seu crescimento mais limitado em solos afetados por sais pelo contato direto com os problemas físicos oriundos do sódio trocável ou pelas inconveniências dos sais solúveis. A matéria orgânica, além de promover melhoria química e biológica ao solo (Silva \& Mendonça, 2007), contribui para a agregação, a retenção de água e ainda a aeração do solo; e, como o biofertilizante bovino possui material orgânico em estado mais humificado que a matéria orgânica que o originou (Lagreid et al., 1999), observa-se que o insumo contribuiu para a redução da densidade do solo e, consequentemente, contribuindo para aumentar o espaço poroso, melhorando o desenvolvimento das raízes, mesmo em ambiente estressante para o maracujazeiro-amarelo. Em estudo da interação salinidade da água x biofertilizante bovino no substrato, mesmo registrando redução do comprimento da raiz principal do maracujá-amarelo irrigado com água salina, Sousa (2006) constatou que os valores foram sempre superiores nas plantas tratadas com o insumo orgânico.

Igualmente ao diâmetro caulinar e comprimento da raiz principal, a interação biofertilizante bovino $\mathrm{x}$ idade das plantas após a semeadura exerceu efeito estatisticamente positivo o sobre a produção de biomassa seca do maracujazeiro amarelo, independente do órgão avaliado (Figura 7). A matéria seca radicular (Figura 7A) foi incrementada com aumento das concentrações de biofertilizante fornecido ao solo à medida que se prolonga o período de avaliação, apresentando valor máximo de $0,91 \mathrm{~g}$ planta $^{-1}$. Os valores de matéria seca do caule (Figura 7B), folhas (Figura 7C) e total (Figura 7D) seguiram a mesma tendência das raízes, registrando-se valores máximos de 0,$99 ; 1,35$ e $3,24 \mathrm{~g} \mathrm{planta}^{-1}$, respectivamente.
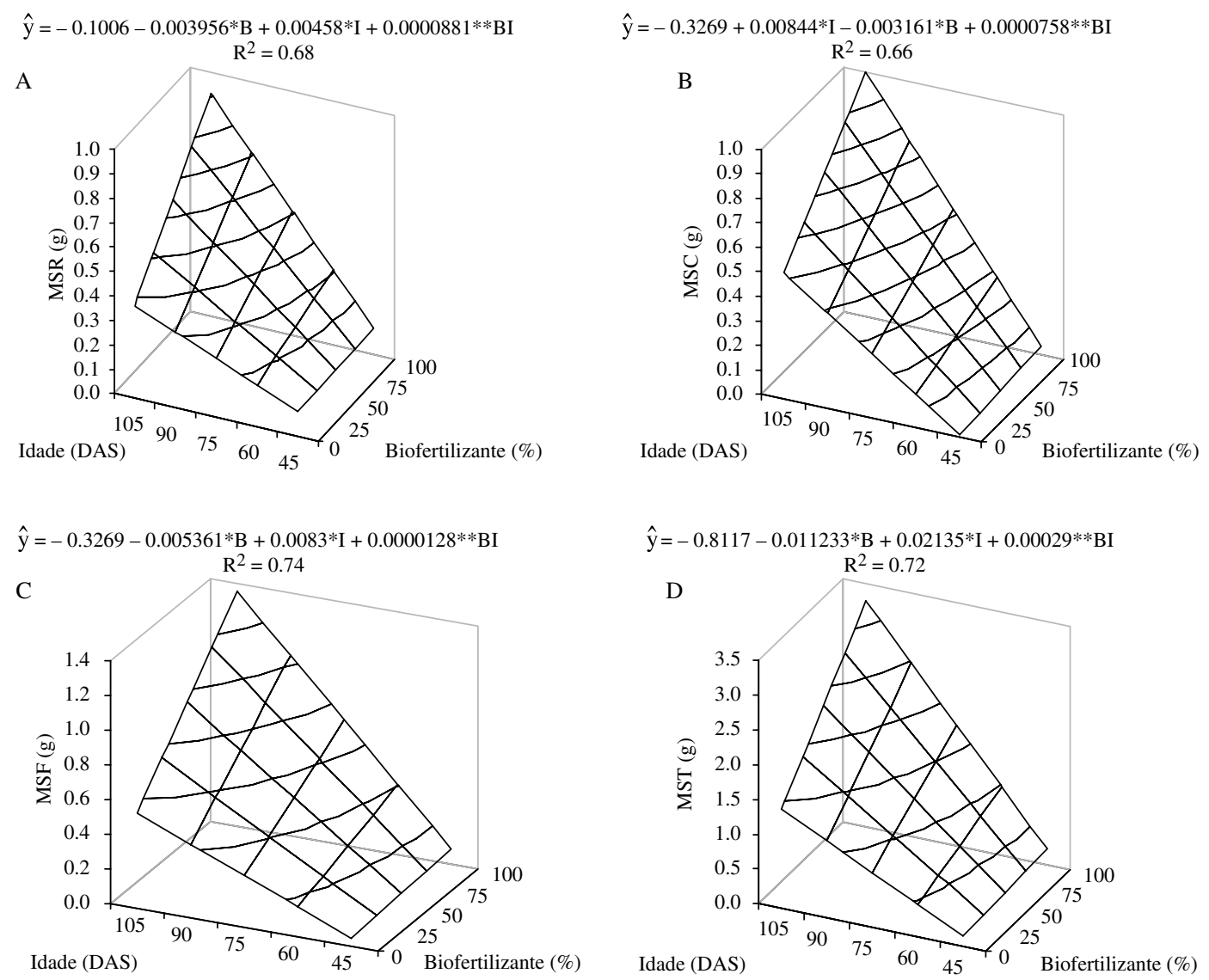

Figura 7. Matéria seca radicular-MSR (A), caule-MSC (B), folhas-MSF (C) e total-MST (D) do maracujazeiro amarelo em função do biofertilizante bovino e idade das plantas após a semeadura (DAS). 
A tendência dos resultados no solo sódico com biofertilizante está de acordo com a registrada por Campos et al. (2009), na fitomassa seca radicular da mamoneira, com Sousa (2006), para a matéria seca radicular e da parte aérea do maracujazeiro e Cavalcante et al. (2010) nas variáveis de crescimento da goiabeira paluma, ambos sob estresse salino da água de irrigação. Esses resultados são compatíveis também com Wu et al. (2005) que concluíram que o biofertilizante em solo não salino, sem inoculação com fungos e bactérias proporcionaram maior biomassa seca do milho em relação a testemunha.

\section{Conclusão}

O aumento das doses de biofertilizante estimulou o crescimento inicial e a produção de matéria seca do maracujazeiro amarelo.

\section{Agradecimentos}

Ao Conselho Nacional de Desenvolvimento Científico e Tecnológico ( $\mathrm{CNPq})$ pelo financiamento da pesquisa e à Coordenação de Aperfeiçoamento de Pessoal de Nível Superior (CAPES) pela concessão de bolsa de pós-graduação ao primeiro autor.

\section{Referências Citadas}

Al-Zu'Bi, Y.

2007 Effect of irrigation water on agricultural soil in Jordan valley: An example from arid area conditions. Journal of Arid Environments, Cambridge, 70: 63-67.

Ansari, A.A.

2008 Effect of Vermicompost on the Productivity of Potato (Solanum tuberosum), Spinach (Spinacia oleracea) and Turnip (Brassica campestris). World Journal of Agricultural Sciences, Madison, 4 (3): 333-336.

Campos, V.B.; Cavalcante, L.F.; Rodolfo Júnior, F.; Sousa, G.G.; Mota, J.K.M.

2009 Crescimento inicial da mamoneira submetido à irrigação com água salina e biofertilizante bovino. Magistra, Cruz das Almas, 21: 40-47.

Campos, V.B.; Cavalcante, L.F.; Morais, T.A.; Menezes Junior, J.C.; Prazeres, S.S.

2008 Potássio, biofertilizante e cobertura morta: Efeito sobre o crescimento do maracujazeiro amarelo. Revista Verde, Mossoró, 3 (1): 78-86.

Cavalcante, L.F.; Vieira, M.S.; Santos, A.F.; Oliveira, W.M.; Nascimento, J.A.M.

2010 Água salina e esterco bovino líquido na formação de mudas de goiabeira cultivar Paluma. Revista Brasileira de Fruticultura, Jaboticabal, 32 (1): 251-261.

Cavalcante, L.F.; Cavalcante, I.H.L.; Santos, G.D.

2008 Micronutrient and sodium foliar contents of yellow passion plants as a function of biofertilizers. Fruits, Paris, 63: $1-8$.

Cavalcante, L.F.; Lima, R.L.S.; Santiago, R.D.; Cavalcante, I.H.L.; Araújo, F.A.R.

2002 Melhoria química e física de um solo salino sódico tratado com matéria orgânica e cultivado com leguminosas forrageiras. Ciência Agrícola, Rio Largo, 6 (1): 27-35.

Chinnusamy, V.; Jagendorf, A.; Zhu, J.

2005 Understanding and improving salt tolerance in plants. Crop Science, Madison, 45: 437-448.

Cruz, J.L.; Pelacani, C.R.; Coelho, E.F.; Caldas, R.C.; Almeida, A.Q.; Queiroz, J.R.

2006 Influência da salinidade sobre o crescimento, absorção e distribuição de sódio, cloro e macronutrientes em plântulas de maracujazeiro-amarelo. Bragantia, Campinas, 65 (2): 275-284.
Empresa Brasileira de Pesquisa Agropecuária-EMBRAPA. 1997 Centro Nacional de Pesquisa de Solos. Manual de métodos de analise de solo. 2da. Ed. Rio de Janeiro: EMBRAPA. (Documentos, 1).

FAO

2004 Statistical databases: agriculture 2004. Roma: 2004. Disponível em: <http://www.fao.org/faostat> Acesso em: 10 de dezembro de 2008.

Ferreira, P.V.

2000 Estatística experimental aplicada à agronomia. 3ra. Ed. Maceió: EDUFAL.

Gheyi, H.R.; Azevedo, N.C.; Batista, M.A.F.; Santos, J.C.R. 1995 Comparação de métodos na recuperação de solo salinosódico. Revista Brasileira de Ciência do Solo, Campinas, 19 (2): 173-178.

Kupper, K.C.; Bettiol, W.; Goes, A.; Souza, P.S.; Bellotte, J.A.M.

2006 Biofertilizer for control of Guignardia citricarpa, the causal agent of citrus black spot. Crop Protection, London, 25: 569-573.

Lacerda, C.F.; Cambraia, J.; Oliva, M.A.; Ruiz, H.A.; Prisco, J.T. 2003 Solute accumulation and distributions during shoot and development in two sorghum genotypes under salt stress. Environmental and Experimental of Botany, London, 49 (1): 107-120.

Lagreid, M.; Bockman, O.C.; Kaarstad, O. 1999 Agriculture, fertilizers and the environment. Cambridge: CABI. 294 p.

Lopes, J.F.B.; Andrade, E.M.; Chaves, L.C.G.

2008 Impacto da irrigação sobre os solos de perímetros irrigados na Bacia do Acaraú, Ceará, Brasil. Engenharia Agrícola, Jaboticabal, 28 (1): 34-43.

Marschner, $\mathrm{H}$.

1995. Mineral nutrition of higher plant. 2nd ed. Academy, New York, 889 p.

Mostafazadeh-Fard, B.; Mansouri, H.; Mousavi, S.F.; Feizi, M. 2009 Effects of different levels of irrigation water salinity and leaching on yield and yield components of wheat in an arid region. Journal of Irrigation and Drainage Engineering, New York, 135 (1): 32-38. 
Oliveira, M.K.T.; Oliveira, F.A.; Medeiros, J.F.; Guimarães, I.P. 2006 Efeito de diferentes teores de esterco bovino e níveis de salinidade no crescimento inicial da mamoneira (Ricinus communis L.). Revista Verde, Mossoró, 1 (1): 47-53.

Richards, L.A.

1954 Diagnóstico y rehabilitación de suelos salinos y sódicos. Departamento de Agricultura de los Estados Unidos de América, 172 p. (Manual de Agricultura, 60).

Santos, A.C.V.

1992 Biofertilizante líquido: o defensivo agrícola da natureza 2da. Ed. Niterói: EMATER-RJ. (Agropecuária Fluminense, 8).

Silva, I.R.; Mendonça, E.S.

2007 Matéria Orgânica do solo. In: Novais, R.F.; Alvarez V., V.H.; Barros, N.F.; Fontes, R.L.F.; Cantarutti, R.B.; Neves, J.C.L. (Eds). Fertilidade do Solo. Viçosa: Sociedade Brasileira de Ciência do Solo, Cap. 6, pp. 275-374

Soares, F.A.L.; Gheyi, H.R.; Viana, S.B.A.; Uyeda, C.A.; Fernandes, P.D.
2002 Water salinity and initial development of yellow passion fruit. Scientia Agricola, Piracicaba, 59 (3): 491497.

Sousa, G.B.

2006 Interação biofertilizante $x$ salinidade $x$ volume de substrato na emergência e crescimento inicial do maracujazeiro amarelo. Dissertação (Mestrado em Manejo de Solo e Água) Centro de Ciências Agrárias. Universidade Federal da Paraíba, Areia. $72 \mathrm{f}$.

Taiz, L.; Zeiger, E.

2006 Fisiologia vegetal. 3ra. ed. Porto Alegre: Artmed, 719 p. Vessey, J.K.

2003 Plant growth promoting rhizobacteria as biofertilizers, Plant Soil, 255: 571-586.

Wu, S.C.; Cao, Z.H.; Li, Z.G.; Cheung, K.C.; Wong, M.H.

2005 Effects of biofertilizer containing N-fixer and K solubilizers and AM fungi on maize growth: a greenhouse trial. Geoderma, Wageningen, 125: 155-166. 